Fronteiras - Revista Catarinense de História | https://periodicos.uffs.edu.br/index.php/FRCH/index

ISSN 2238-9717 | n. 37, p. 134-142, jul.-dez./2021 | DOI: https://doi.org/10.36661/2238-9717.2021n37.12502

\title{
Entrevista com o professor Fernando Penna ${ }^{1}$
}

\author{
Cíntia Régia Rodrigues ${ }^{2}$ \\ Núcia Alexandra Silva de Oliveira ${ }^{3}$ \\ Yomara Feitosa Caetano de Oliveira Fagionato ${ }^{4}$
}

A Fronteiras: Revista Catarinense de História não apenas se propõe a ouvir os leitores em suas demandas, mas toca em temas sensíveis de interesse público. Tendo em vista os ataques e as polêmicas que têm atingido os professores de forma geral, em singular os/as historiadores/as, decidimos convidar o professor Doutor Fernando de Araujo Penna para uma entrevista, como forma de reflexão e para fazer circular as novas questões do ensino de história no contexto da pandemia. Penna é figura reconhecidamente atuante em suas lutas coletivas a respeito do ensino de história e da educação democrática. Tanto que foi condecorado diversas vezes pelo seu trabalho, em destaque cita-se a Medalha Tiradentes, concedida pela Assembleia Legislativa do Estado do Rio de Janeiro (ALERJ), em 2017. Atualmente é professor adjunto da Faculdade de Educação da Universidade Federal Fluminense (UFF), atua como docente no Programa de Pós-Graduação em História Social da Faculdade de Formação de Professores da Universidade do Estado do Rio de Janeiro (FPP/UERJ). Doutor e mestre em Educação pelo Programa de Pós-Graduação em Educação da Universidade Federal do Rio de Janeiro (PPGE/ UFRJ) e bacharel e licenciado em história pela UERJ. Tanto a sua atuação em sala de aula, como enquanto coordenador do Movimento Educação Democrática, esteve debatendo a respeito da educação democrática, se debruçando ao Ensino de história, assim como, analisando e combatendo o movimento "Escola sem partido", sobretudo esta última teve repercussão junto à comunidade de professores. A entrevista que se segue foi realizada no formato de reunião virtual e transcrita. Notadamente pode ser considerada um 'aviso de incêndio', parafraseando Michael Löwy, no qual os leitores podem refletir a respeito de como estamos nos tornando professores em relação ao ensino de tantas disciplinas escolares, e em particular ao ensino de história.

\footnotetext{
${ }^{1}$ Transcrição da entrevista: Adriana Elizabeta Seitenfus. Edição da entrevista: Samira Peruchi Moretto.

2 Professora do Departamento de História e Geografia e do Programa de Pós-Graduação em Educação da Universidade Regional de Blumenau (FURB). Brasil. E-mail: cintiaregia56@gmail.com

${ }^{3}$ Professora no curso de História, no Programa de Pós-Graduação em História e no Mestrado Profissional em Ensino de História (PROFHistória) na Universidade do Estado de Santa Catarina (UDESC). Brasil. E-mail: nucia.oliveira@gmail.com

4 Pesquisadora UDESC e ANPUH/SC - GT Ensino de História e Educação. Brasil. E-mail: yoliveirafagionato@gmail.com 
Fronteiras - Revista Catarinense de História | https://periodicos.uffs.edu.br/index.php/FRCH/index

ISSN 2238-9717 | n. 37, p. 134-142, jul.-dez./2021 | DOI: https://doi.org/10.36661/2238-9717.2021n37.12502

1) Dada a sua trajetória de atuação contra o projeto de lei $\mathbf{n}^{0} .7180 / 2014$ "Escola sem partido", quais permanências ou efeitos desse movimento podem ser sentidos na atualidade no campo do ensino de história da educação básica no Brasil, ainda que o projeto tenha sido arquivado e considerado inconstitucional?

Para pensar sobre quais são as permanências e efeitos do projeto "Escola sem partido", não podemos nos restringir ao projeto 867 de 2015 da câmara - projeto mais antigo em âmbito nacional. Na maioria dos artigos que publiquei sobre a temática, fiz o movimento para ampliar ainda mais esse escopo, pois comecei a entender que o termo "Escola sem partido" é parte de um discurso reacionário mais amplo. Quando eu falo discurso não estou falando só de linguagem, estou falando de atribuição de sentido de práticas. Nesse sentido, a "Escola sem partido" é um dos termos dentro de um discurso reacionário mais amplo que impacta o campo educacional e tenho insistido inclusive que não é o único termo utilizado.

Para entender esse impacto do movimento "Escola sem partido" no campo educacional, vale fazer uma síntese de como foi essa trajetória desde sua gênese. O primeiro fato a ser lembrado é um momento que não teve um grande impacto no cenário nacional até o ano de 2014. Foi quando um deputado do Rio de Janeiro, Flávio Bolsonaro, pede para o advogado Miguel Nagib (que é o coordenador e criador do movimento) para que ele formule um projeto de lei, com as ideias base do movimento. Esse fato é atrelado a chamada "onda conservadora", porém, é importante lembrar que o conservadorismo sempre existiu no Brasil, ele nunca deixou de existir. Essa onda conservadora, que tem diferentes datas como marco, alguns datam como sendo em 2013 ou 2014, porém, desde 2010, até 2020 as pautas conservadoras e reacionárias começam a ganhar força e a se projetar. Diferentes atores políticos como deputados e/ou vereadores começam a se engajar a esse projeto. Faço analogia de que esse projeto se torna uma prancha para surfar nessa onda conservadora, os candidatos (deputados, senadores, vereadores) usam projeto "Escola sem partido" como uma maneira se destacar e se mostrar para esse público reacionário, conservador.

Aproveito e trago um momento que pode ser visto como um marco nessa trajetória de combate o "Escola sem partido", quando na Associação Nacional de História (ANPUH) de 2015, realizada em Florianópolis, fui chamado pelo GT de ensino de história para fazer uma fala sobre este movimento. Eu lembro que a reação dos colegas ali presentes foi muito dividida. Uma parte dos colegas, todos pesquisadores do ensino de história, ficaram assombrados. Eles se perguntavam: como é que aquilo era possível, como havia um material daquela agressividade? Assim como, alguns aproximavam as ações do movimento da censura. O outro grupo gargalhava e dizia "Fernando você está desperdiçando o nosso tempo" e "se tal projeto 
Fronteiras - Revista Catarinense de História | https://periodicos.uffs.edu.br/index.php/FRCH/index

for aprovado a presidente Dilma Rousseff vetará”. Por este fato, eu acredito que o campo progressista demorou a reconhecer a ameaça desse discurso reacionário. Só que fora do âmbito acadêmico, especialmente nas redes sociais, isso ganhava muita força e o projeto foi aprovado no estado de Alagoas em 2016. O resultado final foram mais de 200 projetos no Brasil inteiro entre "Escola sem partido" e projetos anti-gênero. Eu lembro que no ano de 2016 eu viajei para diversos municípios do Brasil, para fazer contraponto ao Miguel Nagib em audiências públicas. Em 2018, o então candidato à presidência Jair Bolsonaro (nos poucos debates nos quais ele compareceu) falava claramente em impor o "Escola sem partido" e combater a ideologia de gênero. No mesmo ano, o projeto aparece atrelado a proposta do candidato, que acaba vencendo as eleições. A vitória deste apoiador eleva o "Escola sem partido" ao seu auge. Em 2019, houve a expectativa de que o projeto ganhasse mais força no âmbito legislativo. Porém, havíamos nos mobilizado e conseguido brecar a aprovação do projeto dentro da Comissão especial e houve um movimento muito intenso de resistência por parte desta Comissão especial, para que não fosse aprovado e assim, o projeto não foi aprovado. Em 2019 é apresentado o novo "Escola sem partido", apresentado pela deputada Bia Kicis (PSL), hoje presidente da Comissão de Constituição e Justiça e de Cidadania (CCJ) da câmara dos deputados. A expectativa então era de que o projeto fosse avançar, entretanto, o projeto não avançou. Quem estava na presidência da Câmara era o Rodrigo Maia que havia se comprometido a não colocar em votação projetos com pautas ideológicas. O advogado Miguel Nagib estava esperando uma sinalização, seguindo o conselho do Bolsonaro, porém, o atual presidente não dá essa sinalização. Assim, ele busca e consegue apoio de empresários para bancarem o movimento. Nagib manifestou publicamente que o movimento iria continuar, com apoio de empresários. Destaca-se que até a atualidade não foi divulgado quem seriam esses empresários apoiadores. Em 2020, nós tivemos, felizmente, os julgamentos no supremo, tivemos ações de inconstitucionalidade apresentadas e pessoas do setor educacional fizeram um movimento muito articulado para pressionar o supremo. Alguns atos legais, que se aproximavam do "Escola sem partido", como a lei do estado Alagoas que vetava os estudos de gênero, foram revistas e caíram. Neste rastro, Miguel Nagib anuncia que vai abandonar o movimento, o que efetivamente parece que ele fez. A página de Facebook do movimento foi fechada e o Miguel Nagib não tem mais atuado publicamente na defesa do movimento. Após esta narrativa, fica a questão: quais são os impactos desse movimento?

Como resposta, em primeiro lugar, é necessário colocar que o projeto "Escola sem partido" está enfraquecido enquanto uma proposta no campo legislativo, mas o imaginário conectado a campanha de ódio aos professores, a perseguição aos professores, assim como, a 
Fronteiras - Revista Catarinense de História | https://periodicos.uffs.edu.br/index.php/FRCH/index

ideia de que os alunos "são como uma folha em branco", a tentativa de privatizar a educação foram questões que permaneceram em circulação. Desta forma, o embate continua. Continua sendo muito grande a perseguição aos professores, e agora a estratégia usada para viabilizar esse discurso reacionário é o homeschooling. Inclusive muita gente acredita que o homeschooling não avançará por conta dos pais, em especial, as mães terem vivenciado momentos complexos com o ensino remoto dos filhos, promovido pela pandemia de covid-19. Eu cedi uma entrevista para um podcast de história recentemente, havia uma pessoa que estava entrevistando uma mãe e ela fala "agora a gente sabe o que é o homeschooling". Porém, uma coisa não tem nada a ver com outra, a vivência dos pais/mães, que estão lidando com seus filhos em casa, não tem similaridades com o projeto de homeschooling. Para sintetizar o projeto "Escola sem partido", enquanto projetos de lei está muito enfraquecido, principalmente por conta das decisões do supremo. O projeto não é mais uma pauta viável para que os grupos reacionários se projetem politicamente. No entanto, os discursos que envolvem: a visão dos estudantes como folha em branco, a visão dos professores doutrinadores, a visão do campo progressista como parte do marxismo cultural, tudo isso continua sendo mobilizado. Assim como a campanha de ódio continua sendo utilizada para avançar outras pautas no campo educacional, como do próprio homeschooling.

\section{2) Quais as funções sociais e éticas dos (das) profissionais de história na sociedade?}

Para esta pergunta, responderei fazendo uma articulação com a pergunta anterior e vislumbrando o campo dos profissionais da educação - focar mais na docência dos professores. Em 2015, quando comecei a falar sobre "Escola sem partido" algo que me incomodava na resposta que algumas pessoas do campo progressista davam para as críticas tecidas e para os argumentos do movimento era: que os professores abusavam da liberdade ensinar para doutrinar os alunos. A resposta do campo progressista era que o professor tinha liberdade de ensinar em sala de aula, tinha liberdade de cátedra e que ele fazia o que ele bem entendesse. Essa resposta não me agradava, assim como gerava inquietações dos pais. É necessário avaliar que se eu sou um pai de um estudante que está na educação básica e eu não conheço o campo educacional, não conheço as funções específicas e eu vejo um professor dizendo que em sala de aula ele faz com meu filho o que ele bem entender dentro da sua liberdade de cátedra, isso não me agradaria. Então, eu já insistia em 2015 que seria necessário para o nosso campo reconhecer alguns limites éticos da nossa atuação. Falo da atuação do professor em sala de aula na educação básica e também no ensino superior. Vocês podem se perguntar: por quê? Respondo que é importante 
Fronteiras - Revista Catarinense de História | https://periodicos.uffs.edu.br/index.php/FRCH/index

para que professor possa explorar plenamente a sua autonomia. A autonomia só pode ser explorada e só pode ser vivenciada de maneira responsável se nós tivermos clareza de quais são esses limites, refletindo assim, na sociedade. A maior parte de nós não acredita nisso, nós não acreditamos que o professor possa fazer o que ele bem entender em sala de aula. Quem trabalha com história sabe o quanto esta aborda temáticas complexas e que geram reações até mesmo negativas de estudantes. Quando trabalhamos com a história e cultura afro-brasileira e indígena e alguns alunos trazem termos pejorativos e alegam que é macumba e que não querem aprender sobre aquilo. Precisamos destacar que não estamos nos atentando aos credos ou fé, mas sim, estamos trazendo questões para discutir manifestações culturais e ninguém pode se negar dialogar com uma outra manifestação cultural. Mas como é que a gente constrói esse diálogo, quais são as temáticas que trazem um compromisso do professor de história? Tem algumas temáticas muito sensíveis, como por exemplo, quando falamos sobre escravidão no Brasil, sobre diáspora africana, sobre questão indígena, sobre a questão ambiental, sobre holocausto, sobre o genocídio armênio da primeira guerra mundial, são algumas temáticas em disputa. Existe uma comissão atuando na Associação Brasileira de Ensino de História pensando nos compromissos éticos na docência em história. Estamos discutindo muito essa ideia de dever de memória. Eu vejo que como historiadores, como professores de história, como atuantes na educação básica e no ensino superior, temos que sensibilizar os estudantes para uma situação na qual os direitos humanos mais básicos de um grupo, de uma etnia, de uma classe social, foram brutalmente desrespeitados. Precisamos enquanto categoria profissional ter um código de ética ou um documento que aponte quais são os limites e quais são os princípios que devem orientar a ação do professor quando ele for confrontado com um dilema ético em sala de aula.

Tivemos uma conquista com a profissionalização do historiador/a. Há necessidade de pelo menos um documento que diga quais são os compromissos éticos dessa categoria profissional, quais são os valores que orientam as nossas ações frente aos dilemas do professor, do pesquisador, do historiador. Todos nós, formadores de professores discutimos isso, mas não temos um documento público - penso como um pacto nosso com a sociedade, dizendo quais são esses compromissos, quais são esses valores. Então eu acho que a gente está num momento muito propício para pensar isso, no que nós temos feito, como por exemplo nessa comissão da Associação Brasileira de Ensino de História (ABEH), sobre compromisso ético da docência em história. Não sei qual será o formato, mas este documento servirá para proteger o professor e o historiador quando ele tiver fazendo a sua atividade e agindo de acordo com esses princípios. Vou dar um exemplo possível para realizamos esta necessidade: pensem um professor que está 
Fronteiras - Revista Catarinense de História | https://periodicos.uffs.edu.br/index.php/FRCH/index

sendo perseguido por discutir gênero, se tivermos o documento, com os compromissos éticos do historiador/professor de história, que afirme que temos um compromisso ético e um dever de memória com relação aos esses grupos que tiveram seus direitos humanos mais básicos desrespeitados, e assim, legitimaria a importância de discutir a questão de gênero. Então se esse professor foi perseguido por discutir gênero, ele poderá afirmar que a comunidade dos historiadores, a comunidade dos professores de história reconhece isso como um dever de memória. Assim, fortalece esses professores que se autocensuram por medo de perseguição e fortalece a autonomia do historiador, do professor.

\section{3) Gostaríamos que você descrevesse sua atuação na Comissão de compromissos éticos do exercício da docência no ensino de história, ligada a ABEH.}

Nós tivemos no ano passado a realização do evento "Perspectivas do Ensino de História", que mobilizou a comunidade que se dedica à pesquisa sobre o Ensino de história. Eu fui chamado pela organização do evento para organizar uma mesa, cujo tema era "Por um código de ética dos professores de história”. Quando fui confrontado com este desafio, pude perceber que nós não temos um acúmulo acadêmico muito grande sobre essa discussão no campo do Ensino de história - foram escritos poucos artigos, pelo que mapeei, encontrei poucos registros. Diferente dos trabalhos no campo da educação, a discussão ética na Filosofia da educação é vasta. Porém, no campo de ensino não tanto. Assim, me perguntei: como vamos fazer essa mesa? Foi assim que organizei uma série de conversas, que chamamos de "Ciclo de conversas - questões éticas da prática docente no ensino de história”. Convidamos algumas pessoas para participar e visualizamos que foi algo muito interessante. No evento, através da mesa denominada "Por um código de ética do professor de história" suscitamos uma polêmica e a assembleia então decidiu continuar com a discussão, criando uma comissão que começou a se reunir agora em 2021.

A primeira coisa que fizemos foi deslocar o foco, não queríamos pensar necessariamente um código de ética por uma série de questões. Desta forma, pensamos em compromissos éticos que apontavam para um documento com formato mais livre. Primeiro, acreditamos ser necessário gerar um acordo dentro da comunidade dos professores de história para fazer esse diálogo com a sociedade, trazendo como exemplo, a questão como gênero. O trabalho da comissão tem sido muito interessante, tem nos propiciado um aprendizado - temos um grupo com pensamento e com referências muito diferentes e acho isso muito bom. Estamos pensando na elaboração de um documento preliminar para apresentar no "Perspectivas", agendado para 
novembro de 2021. Uma coisa que todos da comissão têm insistido, é que falta um documento, falta algum tipo de acordo dentro da comunidade de professores de história, dos historiadores, sobre quais são esses limites, quais são essas discussões. A comissão tem trabalhado de forma belíssima e tem a expectativa de que consigamos levar o documento para discussão no evento, assim, ele ganhará outras formas de debate. Eu acho que o documento poderá servir na formação de professores, dando argumentos quando o professor é confrontado com o dilema em sala de alguma temática, ele estará fazendo algo que ele foi formado para fazer. Precisamos elaborar esse momento que será político e a gente precisa operar ele. Precisaremos elaborar o documento e levar para um grupo maior, depois levar para a ANPUH, depois levar para sociedade. Assim, poderemos afirmar que nossos compromissos éticos da docência em história estão documentados. Os pais e a comunidade em geral poderão ter acesso ao documento e também, poderá talvez, não mais incitar a perseguição aos professores, por exemplo. Esse documento poderá nos ajudar neste diálogo com a sociedade, pelo menos essa é a nossa expectativa. Estou muito confiante no trabalho da comissão, estamos nesse processo de gerar algo para discutir com a comunidade.

4) Uma das questões que nos preocupa muito na atual conjuntura da pandemia de covid19, é o impacto nos processos educacionais e formativos. Você poderia nos relatar as suas preocupações a respeito desses impactos na formação inicial dos futuros professores de História?

Os impactos da pandemia estão em todo campo educacional. Vou trazer primeiro uma perspectiva macro, onde estão as disputas políticas e depois vou falar de uma perspectiva da nossa formação em sala de aula - na formação de professores nas Universidades e nos estágios docência. Primeiro trago a crise, a pandemia é uma crise terrível - eu começo dizendo que a gente não pode naturalizar a quantidade de pessoas mortas e de famílias destruídas. A única palavra que me vem à mente é: terrível. A gente está vivendo uma condução terrível dessa situação, e no meio de tantos horrores, com certeza o campo educacional foi muito afetado. Outros grupos continuam tentando avançar suas pautas em diferentes roupagens, então uma coisa que me preocupa muito é uma naturalização do que agora chamamos de ensino remoto, ensino híbrido - que isso se naturalize e que se perpetue pós pandemia. Eu não estou falando de um ensino à distância de qualidade, eu estou falando dessa loucura que a gente está vivendo, essa improvisação para não romper os elos com os nossos estudantes. Tem grupos que já tentam avançar nessa visão de educação a distância precarizada há muito tempo. Nas discussões sobre as novas diretrizes curriculares nacionais para o Ensino Médio, quem propôs queria colocar 
numa das minutas, que foi barrada no conselho nacional, de haver a educação 100\% (de jovens e adultos) à distância. Ao meu ver, isso é impensável - será um acinte. Um ensino à distância precarizado, tenho receio que isso se naturalize e que seja legitimado pelo atual contexto. Se pensarmos no campo do ensino de história, para mim é a questão central, o agravamento das desigualdades que já vivíamos, ninguém se engana que o acesso ao direito à educação no Brasil era ou será igualitário. Lutávamos por essa igualdade, lutávamos pelo direito à educação como direito democrático ao qual todos têm acesso, mas sabemos que não estava plenamente estabelecido só que a pandemia é um retrocesso gigantesco. Essa desigualdade se ampliou e além disso, como eu disse, as propostas são discussões que a gente precisa fazer. Mas eu não tenho visto a nossa discussão sobre a resolução n ${ }^{\circ} 2$ de 2019 do Conselho Nacional de Educação instituir a Base Nacional Curricular Comum (BNCC). É uma mudança radical. Por exemplo, um aluno de história não veria história no primeiro ano do curso, ele ficaria só com disciplinas pedagógicas. Assim como, ele não teria o tempo para discussão da formação específica da história, como temos hoje. O que ficará será somente o conteúdo presente na BNCC, pois a carga horária específica de história, que antes era maior, vai ser reduzida e ela vai estar restrita só para conteúdos e áreas descritas na BNCC. Então é um retrocesso sem tamanho, é algo assim que a gente precisa enfrentar agora, porque os prazos para implementação estão muito próximos. Existem interesses por trás dessa aprovação. Eu julgo que a gente tem que entender essas políticas não de maneira isolada, mas de maneira articulada. Então teremos que ver a reforma do ensino médio em conjunto com a BNCC, pois a reforma do Ensino médio já inclui na LDB artigo sobre a BNCC, mesmo antes de ela ser aprovada a BNCC do ensino médio fragiliza o lugar da história de maneira brutal. Agora a história está diluída dentro de uma área e essa formação quer transformar os professores em aplicadores da BNCC - vai destruir tudo que a gente entende sobre formação de professores. Por exemplo, esse contexto da pandemia não poderia fortalecer a nossa luta por menos alunos em sala, é uma questão não só pedagógica, mas é também uma questão sanitária agora. Como é que voltaremos a presencialidade? Tudo indica que essa pandemia não vai acabar totalmente não, ela vai ficar mais tempo conosco. Também poderão haver outras pandemias, então está na hora da gente juntar a discussão pedagógica com a discussão sanitária e pensar em sala de aula com menos pessoas, espaços menos cheios, tanto pela questão sanitária quanto pedagógica. Assim, eu acompanho os debates, avalio a dificuldade de fazer uma formação de professores com estágio, sem as escolas abertas e vejo como uma dificuldade muito grande. O contexto que estamos vivendo é um verdadeiro massacre, uma dificuldade gigantesca, mas ao meu entender, estamos fazendo da melhor 
maneira possível e o que é possível nesse contexto. Não é possível mandar os estagiários para uma sala cheia de estudantes. Seria encher mais ainda a sala nesse contexto. Nossa luta tem que ser para que isso não se perpetue, para que isso não seja legitimado. Estou torcendo, mesmo que na contramão dos políticos, que essa pandemia seja controlada. Acho importante nos mantermos unidos enquanto comunidade de professores, de educadores, historiadores para continuar entendendo, lutando para compreender tais mudanças, o cenário político e para nos fortalecer enquanto seres humanos. Esse é o momento no qual temos que inclusive fortalecer todas as lutas, nesse cenário tão difícil. 